\title{
Tecnologias de gênero, dispositivo de infantilidade, antecipação da alfabetização: conflitos na produção de corpos generificados
}

\author{
Maria Carolina da Silva Caldeira' \\ Marlucy Alves Paraíso'
}

\section{Resumo}

Com o processo de ampliação do ensino fundamental, as crianças de seis anos foram inseridas em relações de poder-saber diferenciadas. Ao longo de uma investigação, realizada com o uso de técnicas etnográficas articuladas à análise de discurso foucaultiana, em uma turma de primeiro ano do ensino fundamental de uma escola pública da rede municipal de Belo Horizonte, foi possível perceber que, entre essas novas relações de poder-saber, destacam-se aquelas que articulam o dispositivo de antecipação da alfabetização (que preconiza que as crianças devem estar alfabetizadas ao final do primeiro ano de escolarização), o dispositivo de infantilidade e a tecnologia de gênero. Tendo em vista essa articulação, este artigo tem como objetivo discutir como se dá a produção de corpos generificados nesse currículo. Argumenta-se que a articulação do dispositivo de infantilidade com a tecnologia do gênero é posta em funcionamento no currículo que opera com a antecipação da alfabetização por meio de técnicas de distinção (que separam "coisas de meninos de coisas de meninas", geralmente infantilizandoos/as) e técnicas de responsabilização (que responsabilizam professoras, alunos/as e famílias a assumirem certas funções, tendo em vista o seu gênero) com implicações tanto no processo de alfabetização, como no processo de construção do gênero de meninos/as e professora.

\section{Palavras-chave}

Tecnologia de gênero - Currículo do ensino fundamental Dispositivo de infantilidade - Alfabetização.

I- Universidade Federal de Minas Gerais, Belo Horizonte, MG, Brasil.

Contatos: mariacarolinasilva@hotmail.com; marlucyparaiso@gmail.com 


\title{
Technologies of gender, device of infantilization, advance of literacy: conflict in the production of gendered bodies
}

\author{
Maria Carolina da Silva Caldeira' \\ Marlucy Alves Paraíso'
}

\begin{abstract}
Due to the expansion of primary education, six-year-old children have experienced differentiated power-knowledge relations. During an investigation carried out using ethnographic techniques coordinated with Foucauldian discourse analysis in a class of the first year of primary education of a public school of Belo Horizonte city, in Minas Gerais state, it was possible to notice that, among such new relations of power-knowledge, the ones that coordinated advance of literacy (it advocates that children must be literate by the end of the 1st year of schooling), the device of infantilization and technologies of gender stood out. In view of such coordination, this article aims to discuss how the production of gendered bodies in this curriculum occurs. It is argued that the combination of the device of infantilization with technologies of gender is operationalized in the curriculum that works with the advance of literacy by means of techniques of distinction (which separate "boys' stuff from girls' stuff", usually infantilizing them) and accountability techniques (which place responsibility on teachers, students and families to a take certain functions in view of their gender) with implications both in the literacy process and in the construction of the gender of boys, girls and teachers.
\end{abstract}

\section{Keywords}

Technologies of gender - Primary education curriculum - Device of infantilization - Literacy.

I- Universidade Federal de Minas Gerais, 
0 currículo escolar é um artefato constituído por relações de poder-saber e que está envolvido na produção de diferentes modos de subjetivação. Ao ser um espaço por excelência de experimentações, vivências e práticas, nele operam dispositivos, tecnologias e técnicas que muitas vezes evidenciam conflitos culturais, políticos e discursivos, ao mesmo tempo em que disponibilizam diferentes modos de ser, estar e viver para os/as envolvidos/as no processo de ensinoaprendizagem. Especificamente no currículo do primeiro ano do ensino fundamental, é possível notar a articulação e os conflitos entre dois dispositivos: o da infantilidade e o da antecipação da alfabetização. Esses dois dispositivos atuam em múltiplas direções, acionando estratégias diversas e articulando-se com outras tecnologias a fim de atingir seus efeitos. Neste artigo, analisamos como as práticas de alfabetização operacionalizadas pelo dispositivo da antecipação da alfabetização e pelo dispositivo de infantilidade se articulam à tecnologia do gênero para produzir sujeitos generificados. Para isso, utilizamos informações produzidas por meio de uma pesquisa em uma turma de crianças de seis anos de uma escola pública da rede municipal de Belo Horizonte, que fez uso de técnicas etnográficas pós-modernas e da análise de discurso de inspiração foucaultiana ${ }^{1}$.

A etnografia pós-moderna refere-se a um conjunto de estudos que têm procurado afastar-se tanto das perspectivas clássicas e estruturalistas da antropologia, como de perspectivas hermenêuticas (CALDEIRA, 1988). Esse afastamento se deve à consideração de que a etnografia clássica tinha um caráter colonial, realizando hierarquizações entre a cultura do/a etnógrafo/a e dos/as informantes das pesquisas (RABINOW, 2002) e produzindo verdades que buscavam a estrutura que

1- A pesquisa de campo acompanhou, durante 0 ano letivo de 2013, uma turma de primeiro ano, com o objetivo de analisar os efeitos da articulação entre o dispositivo de infantilidade e o dispositivo de antecipação da alfabetização no currículo e nos modos de subjetivação docentes e infantis. Nas observações, foram acompanhados/as os/as 26 alunos/as da turma e a professora, durante as aulas, atividades coletivas (como jogos, excursões apresentações), recreio e momentos de planejamento da docente. As informações foram registradas por meio de diário de campo, fotografias de alguns momentos e coleta das atividades realizadas em sala de aula. caracterizava o ser humano para além das diversidades culturais (CLIFFORD, 2008). Na perspectiva da antropologia hermenêutica, por sua vez, buscava-se um "significado profundo", que poderia ser acessado por meio de uma "descrição densa" (GEERTZ, 1997). As perspectivas etnográficas pós-modernas partem do "caráter seletivo e parcial da 'verdade' antropológica” (CALDEIRA, 1988, p. 147) e do princípio de que os textos etnográficos produzidos estão envolvidos em relações de poder, que, por sua vez, atuam na produção de verdades sobre os grupos culturais pesquisados. Também consideram que o texto etnográfico é sempre uma produção do/a pesquisador/a, que não deve se ausentar do texto, mas deve deixar claro que foi a sua perspectiva que produziu aquelas informações sobre o grupo pesquisado (CLIFFORD, 2008). Consideram, ainda, que não há um significado profundo escondido nas práticas culturais, mas que todos os significados são produzidos nas relações que se estabelecem, sendo possível acessá-los descrevendo-os e analisando-os sem recorrer a uma essência (RABINOW, 2002) ou a um significado profundo, último ou oculto.

Na pesquisa que deu base a este artigo, as contribuições da etnografia pós-moderna foram fundamentais para compreender as relações que se estabeleciam no currículo investigado. Foi importante estarmos atentas ao fato de que o nosso olhar produzia as informações da pesquisa, que não eram dados que já existiam, mas resultado do nosso processo investigativo, como mostra Paraíso (2012). Além disso, a perspectiva etnográfica permitiu entender as relações de poder que ali circulavam e os múltiplos significados produzidos naquele currículo, que se articulavam e ampliavam as questões relativas à alfabetização. Por meio dessa análise, foi possível perceber como nesse currículo opera a "tecnologia de gênero", em articulação com os dispositivos de infantilidade e antecipação da alfabetização, visando à produção de meninos e meninas que têm características distintas conforme seu gênero. 
0 termo tecnologia do gênero é aqui utilizado inspirado em Teresa de Lauretis (1994), que, baseada na perspectiva foucaultiana, entende tecnologia como um dos instrumentos que opera - ao lado dos discursos e das relações de poder - na produção de subjetividades. Assim, a "tecnologia do gênero" é um mecanismo que aciona técnicas, procedimentos, práticas e discursos para produzir sujeitos que se identifiquem como homens e mulheres, meninos e meninas. Nessa perspectiva, consideramos que o currículo do primeiro ano - ao articular o dispositivo de infantilidade e o dispositivo da antecipação da alfabetização - constitui-se em um dos espaços no qual a tecnologia de gênero é operacionalizada. Afınal, o gênero é "produto de diferentes tecnologias sociais, como o cinema, por exemplo, e de discursos, epistemologias e práticas críticas institucionalizadas, bem como das práticas da vida cotidiana" (LAURETIS, 1994, p. 208). 0 currículo é, certamente, um dos espaços que produzem modos de ser e viver generificados.

No primeiro ano do ensino fundamental, esses modos de ser generificados são produzidos por meio de diferentes procedimentos que ora se articulam, ora se contrapõem aos dispositivos da antecipação da alfabetização e de infantilidade. Dispositivo é entendido aqui como "um conjunto decididamente heterogêneo que engloba discursos, instituições, organizações arquitetônicas, decisões regulamentares, leis, medidas administrativas, enunciados científicos, proposições filosóficas, morais, filantrópicas" (FOUCAULT, 2000, p. 244), com vistas à produção de modos de subjetivação. 0 dispositivo de antecipação da alfabetização, por sua vez, refere-se aos elementos heterogêneos que têm sido utilizados para demandar e justificar que a alfabetização das crianças aconteça o quanto antes, preferencialmente no primeiro ano do ensino fundamental nas escolas públicas brasileiras ${ }^{2}$. Na escola em que foi realizada a pesquisa que subsidia este artigo, esse dispositivo articula-se ao dispositivo de

2- Esse dispositivo atua para, inclusive, garantir que crianças sejam alfabetizadas desde a educação infantil. infantilidade, que, desde a Modernidade, tem atuado para produzir sujeitos infantis.

0 dispositivo de infantilidade, por sua vez, refere-se ao conjunto de elementos que possibilitou que, a partir do século XVI, os seres nos anos iniciais de vida passassem a ser identificados como crianças. Diferentemente de autores/as - como Ariès (1978), por exemplo que consideram que a infância foi "descoberta" na Modernidade, compreende-se aqui que ela é "uma instância suscitada e tornada necessária pelo funcionamento do dispositivo de infantilidade" (CORAZZA, 2002, p. 79). Trata-se, portanto, de uma produção, mais do que uma descoberta; de uma invenção, mais do que uma conscientização da sua existência. As características que distinguem os/as adultos/as das crianças foram, na perspectiva aqui adotada, construídas peça por peça por esse dispositivo, que agiu e continua agindo no sentido de diferenciar e de distinguir adultos/as de crianças.

Partimos do pressuposto, então, de que as práticas cotidianas operacionalizadas por esses dois dispositivos no currículo investigado se caracterizavam como um dos modos de produzir corpos de meninos e meninas e posições de sujeito diferentes, a serem ocupadas por eles/ as em função de seu gênero. Entender o gênero como uma tecnologia significa compreendê-lo como algo que se constitui não por meio de aspectos biológicos, mas por meio de variadas relações de poder-saber, discursos, dispositivos e estratégias. Sendo assim, o argumento aqui desenvolvido é o de que a articulação do dispositivo de infantilidade com a tecnologia do gênero é posta em funcionamento no currículo que opera com a antecipação da alfabetização por meio de técnicas de distinção, que separam "coisas de meninos de coisas de meninas", geralmente infantilizando-os/as, e técnicas de responsabilização, que responsabilizam professoras, alunos/as e famílias a assumirem certas funções tendo em vista o seu gênero, com implicações tanto no processo de alfabetização, como na construção do gênero de meninos/as e da professora. 
Para mostrar como isso ocorre, este artigo se divide em três partes. Na primeira, analisamos como saberes relativos às desinências nominais no ensino de palavras, por meio da técnica de distinção, instituem posições de sujeito diferentes para meninos e meninas, homens e mulheres. Na segunda, mostramos como gestos, atitudes, cores e organização espacial atuam na construção de distinções e de corpos nomeados como masculinos e femininos. Por fim, na última parte, analisamos como a técnica da responsabilização atua tanto no sentido de afirmar certas normas de gênero, como no sentido de desestabilizá-las ao permitir que discursos emergentes associados ao feminismo apareçam no currículo escolar.

\section{A técnica da distinção: ensino das} palavras e da linguagem generificada no currículo

Para o funcionamento do dispositivo de antecipação da alfabetização, o ensino das palavras tem papel central. Afınal, por meio desse dispositivo, o que se espera é que as crianças aprendam a ler e a escrever palavras, ainda que com o objetivo maior de compreender os textos. É a sua escrita que se quer proporcionar, com a intenção de que, no futuro, os/as alunos/as possam escrever seus próprios textos. A necessidade de ensinar a escrita das palavras estava presente no currículo formal da rede municipal de Belo Horizonte (RMBH), em que se apresentava como capacidades a serem consolidadas ${ }^{3}$ pelas crianças no primeiro ano: "Escrever palavras alfabeticamente", "Reconhecer palavras globalmente" e "Decodificar palavras". Grande parte do trabalho desenvolvido na sala de aula investigada era feito para garantir que os/as alunos/as compreendessem como as palavras devem ser escritas e lidas em língua

3- As proposições curriculares da RMBH definem que algumas capacidades deverão ser introduzidas em dado ano escolar, outras deverão ser trabalhadas (o que implica a retomada e 0 trabalho sistemático com as mesmas) e algumas deverão ser consolidadas. portuguesa. Listas de palavras de um mesmo campo semântico, reflexão sobre como escrever palavras de uma parlenda, escrita de títulos de histórias escutadas, associar palavras a desenhos e trabalho com algumas sílabas específicas eram algumas das atividades proporcionadas no currículo a fim de atingir esses objetivos.

No ensino dessas palavras, questões de gênero emergiam ${ }^{4}$. Isso ficava evidente em momentos como aqueles em que se explicava o uso dos artigos e das desinências nominais na língua portuguesa. Nesse momento, ensina-se que "classificamos as pessoas em masculino e feminino. Nós temos o gênero masculino e feminino. As palavras também podem ser classificadas em masculino e feminino" (Diário de campo, 29/08/2013). Para explicar essa regra gramatical, aciona-se a técnica de distinção que afirma que os seres têm dois gêneros. Em um processo que desconsidera que a língua é uma invenção humana que atende a determinados interesses (BAGNO, 2006), parte-se do princípio de que os indivíduos são naturalmente cindidos em dois sexos. A língua serviria apenas para constatar essa realidade e expressá-la de determinada forma. Contudo, quando se ensina esse modo de funcionamento da língua, o que está sendo feito é a inserção dos seres em relações de saber-poder que os constroem com dadas características. Nesse sentido, o poder opera "na própria produção dessa estrutura binária entre 'homens' e mulheres"' (BUTLER, 2003, p. 8). Nesse processo, naturalizam-se as diferenças entre homens e mulheres, ao ignorar-se que elas são construídas quando se marca a diferença linguisticamente.

Embora saibamos que "as palavras, como as ideias e as coisas que elas pretendem significar, têm uma história” (SCOTT, 1995, p. 71), ao ensinar os gêneros das palavras no currículo

4- Apesar do vínculo das questões de gênero com o processo de alfabetização, não foram encontrados muitos trabalhos nos quais essa articulação é feita. Em levantamento bibliográfico nos periódicos classificados como A1 pela Capes em educação, nos últimos cinco anos, foram encontrados 67 artigos com o tema gênero. Desses, quarenta tratam de assuntos relacionados à escola, sendo que onze são pesquisas realizadas no ensino fundamental, e nenhuma trata especificamente de alfabetização. 
investigado sem levar isso em consideração, estabelece-se uma divisão que faz com que o sexo seja encarado como estando antes do processo discursivo que o demarca. Colocar a dualidade do sexo "num domínio pré-discursivo é uma das maneiras pelas quais a estabilidade interna e a estrutura binária do sexo são eficazmente asseguradas” (BUTLER, 2003, p. 25). Além disso, ao diferenciar palavras masculinas de femininas, ensina-se também que posições de sujeito podem ser ocupadas por aqueles/as que serão considerados homens ou mulheres. Na turma investigada, após a explicação de que tanto as pessoas como as palavras têm dois gêneros, são citadas algumas palavras que devem ser classificadas como masculinas ou femininas. No conjunto de palavras masculinas, temos "pai, primo, padrinho e cavalheiro". Já no bloco das palavras femininas, temos "mãe, prima, madrinha e dama”. A construção de pares binários é um dos procedimentos acionados pela técnica de distinção para reforçar o discurso de que as pessoas - e as palavras - são divididas em dois gêneros.

No contexto das práticas de alfabetização operacionalizadas pelo dispositivo de antecipação da alfabetização, outras enunciações ajudam a reforçar a compreensão de que o "mundo das palavras" - assim como o "mundo real" - é generificado. Para escrever o número ordinal "nona”, é feito o nove com a letra a. Explica-se para as crianças que "a palavra é feminina, por isso coloca o A. Se fosse masculina, ia colocar o 0" (Diário de campo, 09/05/2013). Em um exercício de completar a frase "A come milho", as crianças tentam várias hipóteses: pintinho, pintinha, galo, pato. Após várias tentativas, uma delas responde o que era esperado: galinha. Ensina-se, então, o motivo pelos quais as outras possibilidades não eram corretas: a letra $a$ "serve para palavras no feminino" (Diário de campo, 30/05/2013). Quando Fernando 5 questiona se pode escrever "cavala" em outro exercício de

5- Respeitando as regras do Comitê de Ética na Pesquisa e os acordos feitos com os/as pesquisados/as, todos os nomes aqui utilizados são fictícios. completar frases, ensina-se "não, a mulher do cavalo é a égua” (Diário de campo, 29/06/2013).

A definição de posições de sujeito para homens e mulheres fica mais evidente em outras situações desse currículo, nas quais a alfabetização é utilizada para constituir certas relações de poder-saber que definem posições de sujeito a serem ocupadas por homens e mulheres. É o caso, por exemplo, da atividade apresentada na Figura 1, na qual se deveria colocar o que cada profissional faz, refletindo acerca da forma como cada palavra deve ser escrita.

Figura 1- Atividade sobre profissões

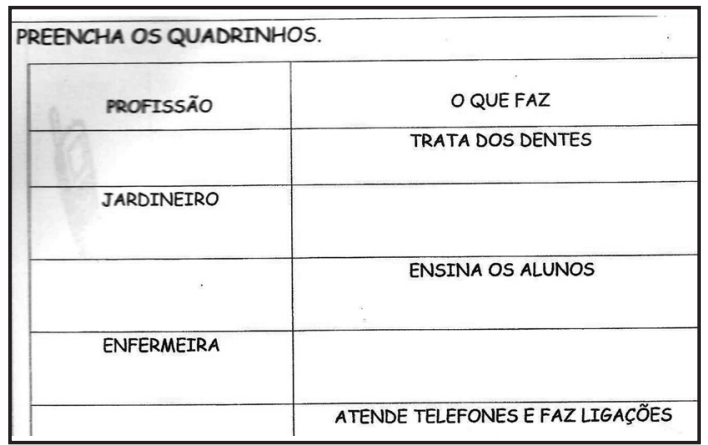

Fonte: apostila 0 mundo ao meu redor, utilizada no currículo investigado para trabalhar saberes relativos a geografia e história. ${ }^{6}$

Após discutir que dentista é quem cuida dos dentes e que a função do jardineiro é cuidar do jardim, pergunta-se "quem ensina os alunos?". As crianças respondem: "A professora”. Acionando mais uma vez a técnica da distinção, explica-se: "Professor, gente, porque quando a gente quer... para se referir a homem e mulher, a gente usa o masculino". Se em outros momentos a técnica de distinção era acionada por meio do procedimento de distinção das palavras masculinas e femininas, aqui ela é acionada pelo procedimento do masculino genérico. Esse é um dos procedimentos mais recorrentemente acionados quando se pretende utilizar a linguagem para excluir as mulheres. Ele

6- A apostila 0 mundo ao meu redor foi organizada pela professora da turma com base em materiais encontrados na internet, atividades disponibilizados em livros didáticos e exercícios por ela produzidos. Esses diversos materiais foram encadernados e cada criança recebeu uma apostila relativa ao tema. 
funciona como um procedimento da tecnologia de gênero que se articula ao dispositivo de infantilidade para produzir infantis-mulheres e mulheres-infantis que aprendam a se ocultar ante à figura masculina. Como aponta Louro (1997a, p. 65-66), “uma das primeiras e mais sólidas aprendizagens de uma menina, na escola, consiste em saber que", quando se usa o masculino genérico, "ela deve se sentir incluída" (LOUR0, 1997a, p. 66, grifos da autora). Por meio desse procedimento, ensina-se que aquele que conta na espécie humana é o masculino. Porém, "a linguagem no masculino não é um 'reflexo do real'; é uma criação linguística intencionalmente política" (FURLANI, 2005, p. 71). Nesse sentido, ao associar-se uma prática de alfabetização às relações de poder que têm colocado mulheres/meninas em segundo plano, a linguagem atua no sentido de estabelecer posições de sujeito para elas.

No caso específico desse exemplo, estabelece-se uma posição de sujeito para "o professor". Ele é quem "ensina as crianças". Ainda que, no Brasil, a maior parte das pessoas que atuam como docentes sejam consideradas mulheres ${ }^{7}$, esse currículo usa o masculino genérico para se referir a quem realiza a função de ensinar. Como aponta Louro (1997b), no século XIX - quando pessoas consideradas homens eram maioria no ensino fundamental -, a principal enunciação para se referir a eles focava na sua capacidade de ensinar. Quando pessoas consideradas mulheres passam a assumir essa função, substitui-se essa enunciação por outras que as vinculam à capacidade de carinho, afeto e cuidado.

0 prosseguimento da atividade narrada anteriormente também permite compreender como, nesse momento no currículo, vincula-se a mulher, e não o homem, às atividades de cuidado. Ainda que se ensine que, quando queremos nos referir a algo que é feito pelos

7- Dados do questionário da Prova Brasil mostram que dentre os/ as docentes que atuam até $05^{\circ}$ ano do ensino fundamental, $10 \%$ se classificam como sendo do sexo masculino e $90 \%$ do sexo feminino. Disponível em: <http://www.qedu.org.br/brasil/pessoas/professor>. Acesso em:13 jan. 2015. dois sexos, usamos o masculino, o quadrinho seguinte aponta a palavra "enfermeira", no feminino, para falar sobre essa profissão. De modo geral, a enfermagem - assim como o magistério - é associada às mulheres. Por ser uma profissão vinculada ao cuidado, estabeleceu-se historicamente que ela é mais adequada para pessoas consideradas do sexo feminino (MEYER, 1996). No currículo investigado, é justamente essa a associação que se cria, já que a resposta considerada correta para preencher o quadrinho é a que a enfermeira "cuida dos doentes". As tentativas de acerto das crianças vão na mesma direção, pois Maria afırma que a enfermeira "cuida dos doentes" e Luiz diz que ela "cuida dos machucados". Vale registrar que doentes e machucados também são utilizados no masculino para se referir a todos/ as, reforçando os efeitos do procedimento do masculino genérico.

A linguagem atua aqui para estabelecer que, se o professor - no masculino - é aquele que ensina, a enfermeira - no feminino - é aquela que cuida. Marca-se um lugar para mulheres e homens, o que mostra que "a linguagem não designa palavras, mas sistemas de significação" (SCOTT, 1995, p. 81). Tal linguagem, ensinada na escola desde muito cedo, reforça certas posições conforme o gênero. Afınal, "se repetimos uma coisa várias vezes, ela se torna normal. Se vemos uma coisa com frequência, ela se torna normal" (ADICHIE, 2014, p. 17). Se, desde o currículo do primeiro ano do ensino fundamental, aprendemos na escola que há profissões e características tidas como femininas e outras como masculinas, não aprendemos a problematizar tais categorizações. Elas se constituem como verdades em nosso modo de agir no mundo. Isso tem efeitos naquilo que meninas e meninos aprendem, já no início da escolarização básica, que podem e devem ser e fazer. Isso pode limitar possibilidades para algumas e aumentar possibilidades para outros.

Pesquisas como a desenvolvida por Sales (2010) evidenciam como, em função de discursos generificadas que circulam em nossa 
sociedade, certas profissões (como a engenharia e a eletrônica) são ocupadas por homens, enquanto profissões vinculadas ao cuidado e à atenção são mais procuradas por mulheres. Esse processo - que não se dá sem resistências, como evidenciado pela autora - atua na manutenção de certas desigualdades de gênero. Pode-se inferir que ele começa muito antes da escolha pelas profissões e que, por meio de exercícios simples como o aqui analisado, são ensinados padrões generificados para as crianças que podem ter influência nos seus modos de ser e agir ao longo da vida. É assim que o ensino das palavras se vincula sutilmente às relações de poder e à tecnologia de gênero.

É claro que esse processo de ensino da linguagem generificada não se faz sem conflitos. Mostrando como as definições gramaticais são arbitrárias, algumas vezes as crianças confundem os sentidos nesse currículo, apresentando outras possibilidades de pensar o "mundo das palavras e dos gêneros”. Na atividade analisada anteriormente, Adryan pergunta para uma das pesquisadoras se é para escrever professor ou professora. A pesquisadora explica que a docente orientou a escrever professor. Ele pede para escrever professora. Perguntado sobre o motivo, o menino diz que é porque não sabe escrever professor. Talvez de fato a criança em questão não tenha ainda aprendido a pequena diferença que existe entre as duas palavras. Talvez seja apenas a ideia de uma distinção generificada das palavras que não tenha sido ainda compreendida pela criança. Ou talvez sua recusa em escrever professor se deva ao fato de que, na esfera escolar em que está inserido, não há professores lecionando e sim professoras. De todo modo, evidencia-se aqui o caráter construído da linguagem, sua mobilidade e as múltiplas possibilidades que se apresentam. Ainda que se designe uma posição e uma palavra para expressar essa posição, a recusa do aluno mostra que há outras possibilidades para pensar a linguagem, mesmo operando dentro da lógica binária ensinada nesse currículo.

A linguagem - assim como as posições de sujeito que ela produz e disponibiliza - vaza, e está sempre aberta a mostrar outras possibilidades. No currículo investigado, essa linguagem é articulada à tecnologia de gênero para produzir posições de sujeito. Porém, essa tecnologia vai além das palavras que se quer ensinar. Ela incide sobre outros aspectos do currículo pesquisado, tanto no sentido de reforçar binarismos, como no sentido de mostrar possibilidades de existência para além dos sentidos usuais. Assim, a técnica de distinção é acionada no discurso do currículo investigado também para produzir corpos considerados femininos e masculinos, como mostramos a seguir.

\section{As cores do gênero: técnica da distinção para produção de corpos generificados}

Apresentar certas práticas, atitudes e características como sendo de meninas e outras como sendo de meninos é algo comum em currículos de diferentes níveis de ensino, o que evidencia como os currículos se caracterizam como um artefato generificado (LOURO, 1997a; SILVA, 2001). No currículo investigado, essas diferenciações também estão presentes. As diferenças entre meninos e meninas eram nomeadas, vividas e, até certo ponto, incentivadas. Cores, esportes, choro, entre outros acontecimentos, são significados de acordo com uma norma de gênero que opera no sentido de estabelecer uma cisão dos corpos em dois gêneros. Um dos procedimentos para isso consistia na identificação do seu corpo como sendo de um menino ou de uma menina, como pode ser visto na Figura 2.

Atividades como essa evidenciam que o processo de construção do gênero passa pelo reconhecimento de que seu corpo se enquadra em determinadas normas que permitem identificá-lo como feminino ou masculino. Na atividade apresentada, aquilo que marca diferencialmente os corpos como masculinos ou femininos é o cabelo e o uso de acessórios (como o brinco na menina). Excetuando esses dois detalhes, os corpos são iguais. Nota-se, porém, um estímu- 
Figura 2- atividade utilizada no currículo investigado para ensinar geografia e história

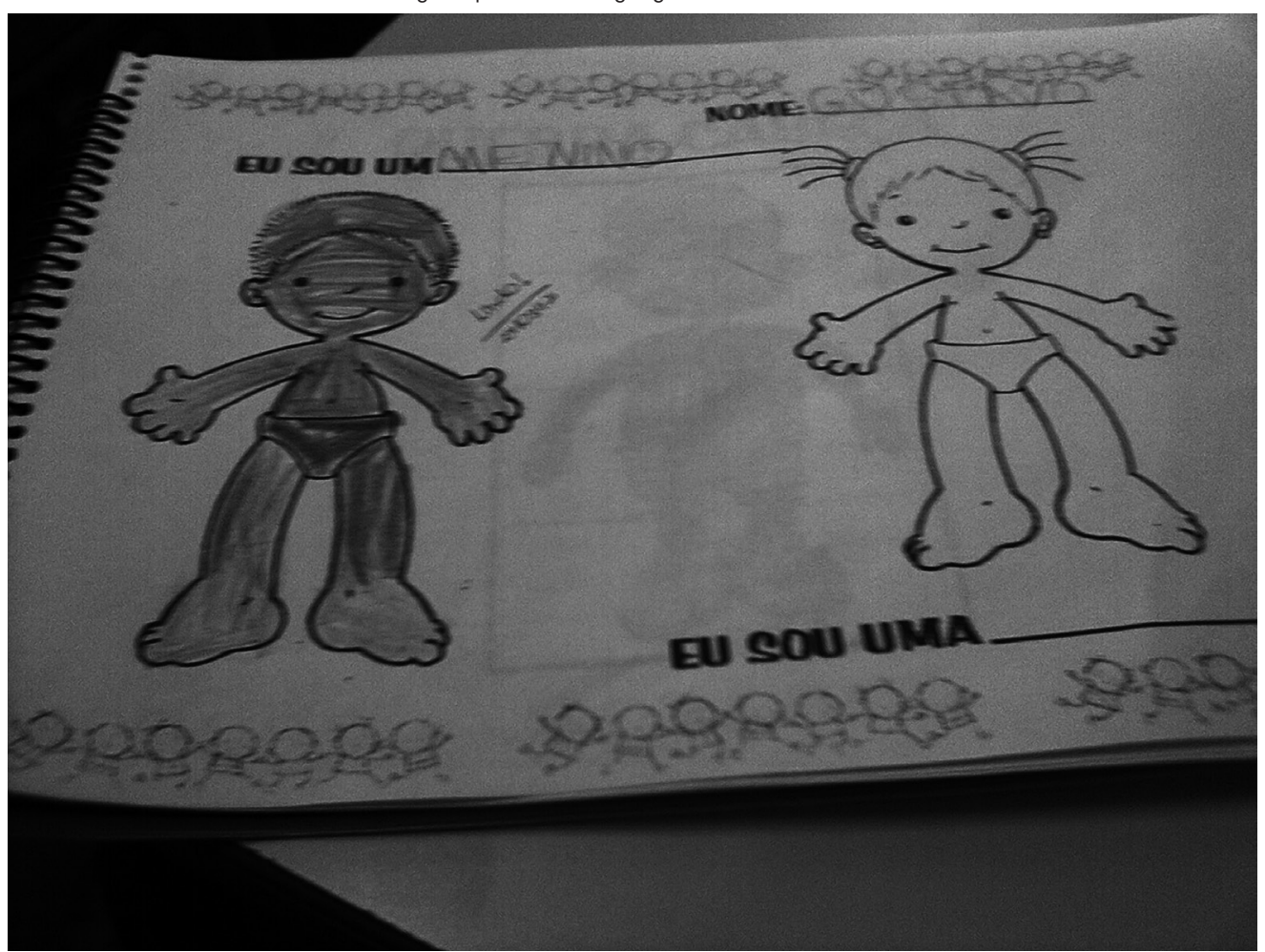

Fonte: apostila 0 mundo ao meu redor.

lo à produção de um corpo feminino que seja marcado pela preocupação com a aparência. As meninas parecem ser "educadas para cultivarem a beleza” (CARDOSO; PARAÍSO, 2015, p. 161) desde os anos iniciais da escolarização, visando ao cuidado com os pequenos detalhes, como brincos e a arrumação do cabelo. Isso ocorre não somente no ensino fundamental, mas também na educação infantil, como evidenciou Carvalhar (2009).

Essa atividade permite analisar também como o entendimento de um corpo como masculino ou feminino é "em si mesmo uma construção” (BUTLER, 2003, p. 27), feita por diferentes discursos, em diferentes momentos históricos. Isso não significa que o corpo seja como um "cabide de pé no qual são jogados diferentes artefatos culturais, especificamente os relativos a personalidade e comportamento" (NICHOLSON, 2000, p. 12). Pelo contrário, o corpo só existe porque os discursos o denominam dessa forma. Essa posição se contrapõe à ideia de um corpo natural, um organismo que pré-existe ao ato do discurso. Como afırma Butler (1998, p. 139), "esse ato de significação produz o corpo que, então, afırma encontrar antes de qualquer significação", ou seja, os discursos que produzem os corpos tratam de ocultar esse processo de construção, fazendo com que se entenda o corpo como algo natural. Dessa forma, pode-se dizer que os "corpos na verdade carregam discursos como parte de seu próprio sangue” (PRINS; MEIJER, 2002, p. 163). No que concerne especificamente às relações de gênero, esse entendimento de corpo problematiza a noção de que o sexo seria anterior ao gênero, de que ele seria "aquilo que está fora da cultura e da história, sempre a enquadrar a diferença masculino/feminino" (NICHOLSON, 2000, p. 10). Por essa razão, 
"não se pode dizer que os corpos tenham uma existência significável anterior à marca de seu gênero" (BUTLER, 2003, p. 27). Sexo e gênero não são, então, diferentes, mas fazem parte de uma mesma cadeia discursiva, que atua no sentido de produzir corpos diferenciados. No currículo investigado, a tecnologia de gênero aciona o procedimento de identificação para dotar corpos nomeados como masculinos ou femininos de determinadas características.

Além desse procedimento, outros são acionados para ensinar a identificar corpos como masculinos ou femininos. No currículo pesquisado, incentiva-se um procedimento de modelagem dos corpos para produzi-los. Na brincadeira da música Tumbalacatumba, por exemplo, canta-se: "quando o relógio bate as onze, todas as caveiras fazem pose”. Nesse momento, instrui-se: "Pose de meninos e pose de meninas”. As meninas fazem poses com a mão no rosto, meigas. Os meninos fazem poses de braços cruzados e cara de mau (Diário de campo, 02/05/2013). 0 corpo passa a ser usado para construir aquilo que se espera de cada um dos gêneros. Dotam-se certos gestos de características associadas aos homens e às mulheres. Uma pose é construída e o corpo passa a ser considerado como masculino ou feminino. Isso evidencia como "as propriedades do corpo - andar, sorrir, cavar, nadar - não são propriedades naturais, mas conquistas técnicas" (ROSE, 2001, p. 169). 0 mesmo ocorre com as propriedades consideradas como sendo de um gênero. Elas são produzidas por meio da modelagem dos corpos e da sua adequação a determinados padrões de gênero.

Além de modelar o corpo, era preciso colori-lo com determinadas cores. 0 procedimento de usar cores distintas - um dos mais comuns no que se refere aos meninos e às meninas - operava no currículo de diferentes formas. A diferenciação de cores estava presente nas atividades, nos materiais, nas roupas e nos brinquedos. Em certo momento, por exemplo, Júlia mostra o espelho do seu relógio cor-derosa (Diário de campo, 01/06/2013). Em outro episódio, Yasmin diz para Sarah terminar logo sua atividade; do contrário, não sobrarão massinhas de modelar cor-de-rosa para que elas brinquem (Diário de campo, 06/06/2013). Após as férias escolares do meio do ano, Raylane tem uma nova mochila, que é amarela. Maria questiona porque ela não escolheu uma rosa (Diário de campo, 03/08/2013).

Se considerarmos que o corpo não se refere apenas ao organismo material, mas é também uma "superfície formatada por vestimentas, adereços, gestos e comportamentos" (FREITAS, 2008, p. 108), é possível entender que esses diferentes materiais e atitudes estão modelando corpos considerados femininos, colorindo-os com a cor rosa. Essa associação das meninas com o rosa é uma das normas mais insistentemente ensinadas por diferentes artefatos culturais, repetida por diferentes discursos, chegando até o meio escolar. Ela está presente: na decoração de quartos de bebês, nos quais para as meninas predominam cores como o rosa, vermelho, lilás, enquanto para os meninos aparecem o azul, o verde e o amarelo (SANTOS, 2004, p. 76); nas roupas a serem usadas por meninas, nas quais, de modo geral, impera o rosa; nos brinquedos para elas, que - além de serem associados ao doméstico - também são marcados pela cor rosa. Os cadernos escolares apresentam predominantemente essas cores, como mostra Carvalho (2012). Ao analisar cadernos de alunos e alunas do ensino fundamental, ela notou como os cadernos das alunas eram considerados "cadernos cor-de-rosa" pelas docentes, seja pela presença massiva dessa cor, seja pelo uso de detalhes e pelo capricho. Esses diversos elementos evidenciam como a construção do gênero passa pelo uso de determinadas cores.

Na técnica de distinção que estabelece que há cores para meninos e cores para meninas, não basta que alunas estabeleçam que sua cor preferida é o rosa. É preciso que os meninos rechacem essa cor. Para que essa oposição seja construída, é preciso atribuir a um grupo “todas as características positivas possíveis em relação às quais as outras identidades 
só podem ser avaliadas de forma negativa" (SILVA, 2000, p. 83). Assim, se o rosa é cor de menina, um menino que escolhe essa cor deve ser avaliado negativamente. É o que ocorre em alguns momentos, como quando Fernando pede a massa de modelar "rosinha" e Kauan o recrimina, chamando-o de "mulherzinha" (Diário de campo, 06/06/2013). Para garantir que a técnica de distinção funcione, é importante policiar as fronteiras (LOURO, 2004), demarcando o que deve ser vivido por meninos e meninas em termos de gênero. Para isso, um procedimento de recriminação é acionado no currículo. Uma técnica de dominação (FOUCAULT, 1993) - no sentido de que é exercida pelo outro, delimitando a ação de um primeiro - é acionada para garantir que certas vivências e experiências sejam possíveis.

Além de técnicas de dominação, para garantir a diferenciação, é importante também acionar técnicas de si (FOUCAULT, 1993). Assim, é preciso que cada criança se reconheça como sujeito de um gênero e assuma para si uma posição em função de seu gênero: "Essas 'posições' não são meros produtos teóricos, mas princípios organizadores totalmente embutidos de práticas materiais e arranjos institucionais" (BUTLER, 1998, p. 24). Assim, uma posição de sujeito que gosta de rosa é produzida para meninas e uma posição de que não gosta é marcada para os meninos. Isso se dá não apenas pela repressão pelo gosto de alguns, mas também pelo próprio reconhecimento e introjeção dessa norma.

Isso pode ser percebido em diferentes momentos desse currículo, como quando, por exemplo, Adryan pergunta para Matheus se uma tesoura cor-de-rosa é sua e ele diz: "Não! Tá maluco! Sou homem" (Diário de campo, 10/07/2013). Reconhecer-se como sujeito de um gênero implica negar as outras possibilidades. Para se construir como homem, é preciso negar aquilo que é associado às mulheres. É necessário acionar uma técnica de si, em que não apenas se marca aquilo que se é, como também se define aquilo que não se é, ou, como afirma Rose (2001, p. 187) "para ser o eu que $a$ gente é, a gente não deve ser o eu que a gente não é - não aquela alma desprezada, rejeitada ou abjeta" (grifos no original). Há, dessa forma, um processo no qual as meninas e aquilo de que elas são ensinadas a gostar é inferiorizado, enquanto os meninos e seus desejos são, nesses momentos, considerados como superiores. Gostar de rosa para um menino seria algo de "maluco", algo vinculado ao irracional, ao errado, ao perigoso.

Esse procedimento de normalização para a produção de uma posição de sujeito homem atua não apenas no momento em que alguém diz que é alguma coisa (como quando Adryan afırma ser homem). Ele também se evidencia pela negação daquilo que não se quer ser. Esse processo de sujeição à norma e de negação de certas vivências torna-se visível quando Adryan diz: “Quem é gay levanta a mão". Rapidamente, todos os meninos abaixam a mão (Diário de campo, 28/03/2013). Aqui, mais importante do que marcar o que se é (talvez, heterossexual), é marcar aquilo que não se é: gay. Posições de sujeito são construídas por esse procedimento de negação da identidade, bem como pelo procedimento da afirmação daquilo que se é (SILVA, 2000, grifos nossos). No processo de construir posições de sujeito para os infantismeninos, ensina-se que não se deve gostar do rosa, nem assumir identidades gays.

Se, por um lado, há um processo de reafirmação de certas cores como femininas ou masculinas, por outro, enunciações diferentes aparecem, estabelecendo descontinuidades nesse processo. É o que se nota quando, ao distribuir massinhas para as crianças brincarem, Sarah e Yasmin começam a dizer que querem a massinha rosa. A professora ensina: "Todas as cores são bonitas e eu não tenho rosa para todas as meninas que pedirem rosa, nem azul para todos os meninos que pedirem azul, nem vermelho para quem quiser vermelho. Então, a massinha vai ser a que cair na hora". Um menino concorda com a professora e diz que seu tio tem uma camisa cor-de-rosa (Diário de campo, 
25/04/2013). Aparece ainda no momento em que, em duplas, as crianças devem colorir uma trilha de um jogo matemático. Pedro sugere para Eric - que é sua dupla nessa atividade - colorir o caminho de verde. Eric sugere: "que tal colorir metade de rosa e metade de verde?" 0 menino aceita (Diário de campo, 28/06/2013). Ao mesmo tempo em que se marca o gênero com determinadas cores, produzindo corpos que se expressem e se coloram com elas, discursos concorrentes aparecem, problematizando tais marcas culturais e abrindo outras possibilidades para as vivências de meninos e meninas nesse currículo.

Separações nos momentos de práticas esportivas também são acionadas para diferenciar corpos de meninos de corpos de meninas. Como já evidenciado em variadas análises, o futebol é considerado em nosso país um dos mais importantes artefatos para a produção de sujeitos generificados (REIS, 2011; ALTMANN, SOUZA, 1999; SALES, 2010). De modo geral, ele é associado aos meninos, atuando na produção de corpos ativos, enquanto as meninas não são incentivadas a participarem dessas práticas, como mostrou Reis (2011), em sua pesquisa que investigou a produção de corpos-meninos no ensino fundamental. Isso ocorre no currículo investigado. Embora não haja uma distinção por parte das docentes com relação ao futebol, as próprias crianças parecem assumir essa norma de gênero. Leandra, por exemplo, recusa-se a participar de uma prática esportiva por dizer que vai bagunçar seu cabelo. Ela fica conversando com uma das pesquisadoras, que questiona o motivo da sua não participação na atividade. Ela diz que não gosta de queimada nem de futebol, porque são coisas de menino e ela só joga na educação física porque é "obrigada" (Diário de campo, 22/10/2013).

Ser obrigada a participar de certas práticas parece ser um procedimento que, no currículo investigado, busca desestabilizar a técnica da diferenciação de meninos e meninas. Obriga-se Leandra a jogar futebol sob a alegação de que vai ajudá-la a desenvolver- se (Diário de campo, 22/10/2013). Esse desenvolvimento pode ser entendido como uma forma de produzir um corpo feminino ágil e ativo. Talvez isso ocorra pela força de outro discurso que circula na sociedade atual e considera o sujeito sedentário inadequado. Por isso, divulga-se a importância do estilo de vida ativo. Esse estilo de vida, na perspectiva aqui adotada, é entendido como "mais do que uma simples opção pessoal pela prática de exercícios regulares em prol da saúde”. Isso porque essa demanda, "de modo muito sutil, inscreve nos corpos normas de conduta e comportamento" (FRAGA, 2005, p. 102). Talvez o fato de ser obrigada a participar de certas práticas que não são o seu desejo possa ser entendido também como um modo adulto de exercer poder sobre as crianças. Aparentemente, mais importante do que garantir uma norma de gênero, é manter o cumprimento das regras escolares e daquilo que está estabelecido no currículo como conhecimento importante. Afinal, é pouco provável que, nesse currículo, fosse permitido a Leandra não fazer alguma das atividades das outras aulas com base em alegações de gênero. 0 dispositivo da infantilidade que estabelece o controle adulto sobre os/as infantis entra em conflito com a tecnologia de gênero operacionalizada nesse currículo, demandando aqui uma menina que seja ativa e que siga as normas escolares. Talvez por se considerar que a disciplina é algo fundamental para o processo de alfabetização e para uma escolarização bemsucedida, deixe-se de lado as posições de sujeito historicamente constituídas para meninas, a fim de garantir que elas sigam as normas adultas estabelecidas na escola de ensino fundamental.

Situações como essa mostram que "o gênero nem sempre se constitui de maneira coerente ou consistente nos diferentes contextos históricos, porque o gênero estabelece intersecções com modalidades raciais, classistas, étnicas, sexuais e regionais" (BUTLER, 2003, p. 20). Na articulação entre o dispositivo de infantilidade e a tecnologia de gênero, há um enfraquecimento de uma das técnicas acionadas 
pela tecnologia de gênero - a técnica de distinção - para se garantir o cumprimento das normas escolares. Parece ser mais importante respeitar as fronteiras que estabelecem que quem faz escolhas são os/as adultos/as do que respeitar aquelas que demarcam que o rosa é uma "cor de menina" ou que jogar futebol é "coisa de menino". Embora haja resistência por parte das crianças, há um esforço para garantir que outros significados sobre gênero estejam presentes no currículo escolar. Esses outros significados advêm de diversos discursos, inclusive daqueles que incorporam partes de um determinado discurso feminista e lutam pela sua inclusão no currículo escolar. São esses discursos que circulam no currículo investigado que analisamos no próximo item.

\section{“Agora, eu não sou uma professora heteronormativa": técnica da responsabilização para produção de sujeitos generificados na alfabetização}

A frase que intitula este tópico foi dita pela professora da turma investigada no dia 01/10/2013, no "horário de projeto". A docente estava montando um calendário para o mês de novembro e colou nele a Figura 3:

Figura 3- Tirinha colada no calendário do mês de outubro.
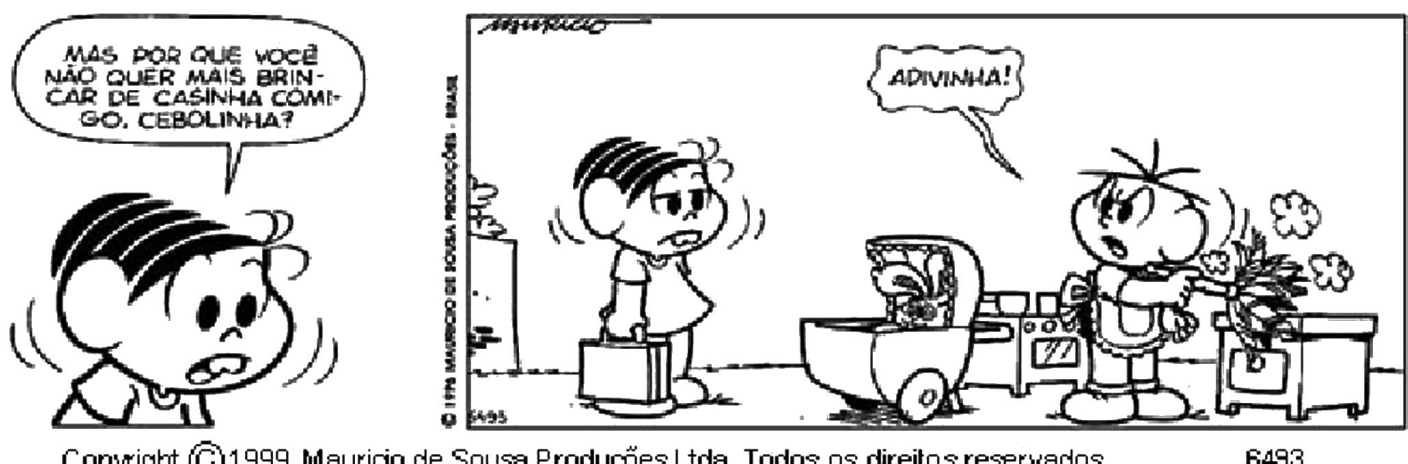

Copyright (Q1999 Mauricio de Sousa Produçoses Ltda. Todos os direitos reservados.

6493

Fonte: Maurício de Sousa Produções Ltda.

No dia anterior, a professora havia produzido junto com as crianças um brinquedo que tinha como base duas tartarugas: uma marcada com características socialmente atribuídas a mulheres e outras com características atribuídas aos homens. A professora se dirige até uma das pesquisadoras e diz: "Meu marido ${ }^{8}$ viu essa atividade e disse que eu sou uma professora muito heteronormativa". Questionada sobre o motivo de ele ter dito isso, a professora conta que ele está fazendo o curso "Educação sem homofobia" e que agora fica analisando tudo com base no que discute no curso.

8- 0 marido da docente também é professor.
A percepção de que alguns/algumas docentes desenvolvem práticas heteronormativas já foi demonstrada por diferentes pesquisas. Finco (2013, p. 182), ao analisar a prática de professoras da educação infantil, constatou como o "poder disciplinar heteronormativo alastra-se gradativamente sobre o conjunto das relações sociais". Carvalhar (2009) também percebeu, em sua pesquisa na educação infantil, uma série de práticas que visam à produção de identidades heterossexuais. Por meio dessas e de outras pesquisas, é possível perceber

9- Horário de projeto é o nome dado pelas docentes para o momento em que a professora planeja as atividades, enquanto os/as alunos/as têm aulas de educação física e arte. 
como a escola está atrelada à produção da heterossexualidade como norma.

Isso não se dá, todavia, sem conflitos, já que discursos anti-homofóbicos ou antiheternormativos vêm sendo produzidos, divulgados e demandados por diferentes grupos sociais. No campo do currículo, esse discurso também ganha visibilidade. Ao se mostrar que o currículo é sexista, classista, racista, heterossexual e homofóbico (SILVA, 2001), diferentes movimentos sociais passaram a lutar para que princípios menos discriminatórios fossem inseridos no currículo. Discursos antidiscriminação chegaram à pesquisa educacional e às escolas. No caso aqui analisado, esses discursos acionam a técnica de responsabilização, que faz com que a docente reflita sobre sua prática, redirecionando-a e tentando incluir no currículo atividades que problematizem as divisões entre os gêneros, particularmente a hierarquização que coloca os homens como superiores às mulheres.

Para garantir a construção da posiçãode-sujeito professora não heteronormativa, a técnica da confissão é acionada. Confessarse significa "declarar em alto e bom som e de maneira inteligível a verdade acerca de si próprio" (FOUCAULT, 1993, p. 203). No caso analisado, a docente aciona a fala de outrem para dizer algo sobre si, algo que não está de acordo com aquilo que vem sendo pregado no campo educacional como adequado. A confissão está relacionada a um tipo de julgamento. Após narrar seu comportamento para outro/a, aquele/a que confessa precisa avaliar o que fez e para isso é necessário, como sugere Larrosa (1994, p. 74), "um critério ou um padrão que lhe permita avaliar o que vê”. 0 critério apresentado para a professora se refere a discursos que têm instituído como inadequada a apresentação de padrões generificados únicos. Nesse sentido, a confissão está diretamente vinculada às relações de poder, já que o critério é estabelecido de acordo com alguma norma fixada em função das relações de poder existentes. Pode-se perceber, no currículo investigado, alguns deslocamentos em relação a certas relações de poder, como as apresentadas no tópico anterior, que buscam diferenciar meninos e meninas, fixando suas posições. A tirinha apresentada representa também uma tentativa de deslocar aquilo que historicamente vem sendo articulado como função de homem ou de mulher.

É interessante notar como a professora coloca-se na posição de sujeito faltoso, procedimento bastante utilizado pelo dispositivo de infantilidade para marcar tanto as crianças, como outros indivíduos considerados infantis (WALKERDINE, 1995). Falta a ela um saber sobre como operacionalizar os discursos antidiscriminação no currículo. Na articulação entre a tecnologia de gênero e o dispositivo de infantilidade, marca-se a professora-mulher como aquela que, por estar em falta, precisa realizar alguma operação sobre si mesma a fim de mudar suas práticas.

Dessa forma, para construir essa posição de sujeito professora não heteronormativa, é necessário avaliar-se, confessar-se e modificar-se. Esses discursos definem que a docente precisa reconhecer que é heteronormativa para construir outro eu. Há um processo de responsabilização da docente pela sua própria mudança, acionado por uma técnica de responsabilização. Para modificar-se, é preciso que a docente assuma determinada posição de sujeito e, ao mesmo tempo, negue essa posição. A confissão está ligada à produção de verdades sobre si mesmo. Entretanto, essa verdade produzida implica uma "recusa do eu, o romper consigo próprio" (FOUCAULT, 1993, p. 215). No processo de confissão, o sujeito cria um eu duplicado que precisa ser negado a fim de construir outra posição de sujeito. Sendo assim, é possível afirmar que "o duplo que essa pessoa constrói quando se olha, se diz, se narra ou se julga está implicado naquilo que a pessoa pode e deve fazer consigo mesma" (LARROSA, 1994, p. 82). 0 duplo produzido é a matéria sobre a qual o indivíduo deve agir para modificar-se. No currículo investigado, trata-se de assumir provisoriamente a posição de sujeito heteronormativa, para, em 
seguida, negá-la e afırmar-se como não estando mais a ocupá-la. A técnica de responsabilização é acionada para desestabilizar a técnica de distinção, fazendo com que a prática de distinguir meninos de meninas seja contestada no currículo investigado.

Cabe, porém, questionar que entendimento de heteronormatividade e que possibilidades de conhecer são instauradas por essa técnica de responsabilização. A heteronormatividade é um termo utilizado para falar da ordem compulsória entre sexo, gênero e sexualidade (BUTLER, 2003). Segundo essa regra, nascer com um sexo implica viver certas características de um gênero e voltar o seu desejo sexual para pessoas de outro sexo. Porém, ao ser assimilada no currículo investigado, a heteronormatividade é traduzida como uma nova norma, segundo a qual é preciso questionar certos padrões de gênero. Contudo, a matriz heterossexual que está na base da ideia de heteronormatividade não é problematizada, já que se mantêm casais heterossexuais como padrão, como pode ser visto na tirinha apresentada neste artigo. Vale destacar que não se pretende, com essa análise, mostrar a inadequação de discursos anti-homofóbicos no currículo escolar. Longe disso. 0 que se pretende aqui é evidenciar que "as questões que colocamos em exame (identidades, práticas, instituições) podem ser, ao mesmo tempo, muitas coisas" (LOUR0, 2007, p. 238). Nesse sentido, queremos explicitar que um discurso é concomitantemente deslocamento em relação a certas normas e estabelecimento de outras normas.

Ao apresentar o calendário com a tirinha que abre esse tópico, houve na sala uma discussão sobre o motivo do Cebolinha estar triste e não querer mais brincar. Nesse momento, ensina-se que as tarefas domésticas "podem ficar divididas, não pode? 0 homem pode ajudar a mulher e a mulher pode ajudar o homem, não pode?" (Diário de campo, 01/10/2013). Aciona-se a técnica da responsabilização para garantir aquela que tem sido uma importante demanda das mulheres: a divisão das tarefas domésticas. Ainda que as crianças possam ter resistência a isso, já que algumas consideram que isso é papel da mãe, esse currículo aciona um procedimento de desestabilização da divisão desigual das tarefas domésticas ao colocar um personagem considerado do sexo masculino em tarefas que historicamente foram associadas às mulheres. 0 uso de um gênero textual bastante presente em turmas de alfabetização faz com que a linguagem seja aqui utilizada para desestabilizar certos padrões e produzir uma posição de sujeito masculino responsável pelas tarefas domésticas.

De modo semelhante, a repetição da enunciação "quem bate em mulher é covarde" é acionada no currículo investigado para produzir uma posição de sujeito masculino responsável pela não agressão. Assim, quando Gustavo bate com a régua em Raylane, Nicolas afirma "quem bate em mulher é covarde" (Diário de campo, 02/07/2013). De modo semelhante, quando Luiz bate em Karen, Mateus afirma "homem não pode bater em mulher" (Diário de campo, 18/09/2013). Nas duas situações, a intervenção da docente é no sentido de afırmar que ninguém pode bater em ninguém, ou seja, bater, independente do sexo/gênero, é algo inadequado. Cabe registrar que a luta para que as violências contra qualquer ser humano sejam evitadas no currículo escolar e na sociedade como um todo não pode significar a ausência da nomeação da violência que ocorre dos homens em relação às mulheres. Isso não significa vitimizá-las, mas dar visibilidade a um processo ainda presente em nossa cultura e que necessita de intervenções diretas para que seja modificado. Opera-se nesse currículo com uma lógica multicultural humanista (SILVA, 2001) que preconiza o respeito e a convivência, mas que pouco problematiza a construção de relações desiguais de poder.

No currículo investigado, apesar dessa intervenção, as crianças continuam a operar com a lógica de que a agressão a alguém considerado do sexo feminino é mais grave do que aquela que ocorre entre duas pessoas consideradas 
do mesmo sexo. Percebe-se, assim, uma responsabilização e uma repreensão daqueles que se envolvem em práticas como essa. Talvez essas enunciações sejam um indício da presença de parte dos discursos feministas no contexto escolar. Afinal, como afirma Luz (2009, p. 62) "a naturalização da violência contra a mulher foi desmistifıcada devido à ação mundial do feminismo". Pode ser também resquício de uma espécie de cavalheirismo que situa o homem no lugar de protetor das mulheres. Parece que, aqui, o dispositivo de infantilidade articula-se à tecnologia do gênero para colocar mulheres em posição de quem precisa ser cuidada e não em posição de igualdade. Não há, no currículo investigado, uma problematização que leve à percepção do processo duplo de necessidade do combate à violência à mulher, sem colocá-la em posição subalterna. Cabe registrar também que esse dispositivo atua no sentido de ensinar aos meninos como eles devem se comportar quando adultos. A técnica de responsabilização é acionada tanto para desestabilizar a posição de sujeito homem agressivo, como para produzir um adulto que cuide das mulheres.

Se considerarmos que todos esses elementos aqui analisados constituem-se em elementos linguístico-discursivos, fica evidente como o gênero é construído como um texto que marca os corpos e constitui modos de ser e estar no mundo. As palavras, gestos, cores, posturas, poses e imagens constroem uma cadeia discursiva que, muitas vezes, aprisiona esses modos, ao criar posições de sujeito fixas e que visam à estabilidade, como mostrado ao longo do artigo. Porém, nenhum desses elementos se caracteriza pela fixidez. As palavras e as coisas que elas podem vir a nomear são fluidas e instáveis. No processo de desestabilização das normas de gênero tão reiteradamente ensinadas em múltiplos espaços, é preciso começar a "usar algumas palavras que ainda não tenham idioma” (BARROS, 2009). Com isso, talvez seja possível mudar alguns significados e construir novos. Talvez seja possível entrar em uma lógica infantil, mudar a função dos verbos e fazer a linguagem delirar formando e transformando sentidos, discursos e corpos. Os/as infantis, quando vivem o currículo do primeiro ano do ensino fundamental, mostram algumas desestabilizações na linguagem da escola. Ainda que, muitas vezes, eles/as estejam sob as regras do espaço escolar, é possível verificar que há escapes e criações no currículo. Dar espaços para essas criações no currículo escolar pode ser um dos modos para desestabilizar normas de gênero e construir outros modos de ser e estar no mundo que fujam aos padrões generificados.

\section{Referências}

ADICHIE, Chimamanda. Sejamos todos feministas. São Paulo: Companhia das Letras, 2014.

ALTMANN, Helena; SOUSA, Eustáquia. Meninos e meninas: questões de gênero e suas implicações na Educação Física. Cadernos do Cedes, Campinas, v. 19, n. 48, 1999, p. 52-68.

ARIĖS, Philippe. História social da criança e da família. Rio de Janeiro: Guanabara, 1978.

BAGNO, Marcos. Nada na língua é por acaso. Presença Pedagógica, Belo Horizonte, v. 12, n. 71, set./out. 2006, p. 22-29.

BARROS, Manoel de. 0 livro das ignorãças. 16. ed. Rio de Janeiro: Record, 2009.

BUTLER, Judith. Fundamentos contingentes: o feminismo e a questão do pós-modernismo. Cadernos Pagu, Campinas, n. 11, 1998, p. 11-42.

BUTLER, Judith. Problemas de gênero: feminismo e subversão da identidade. Rio de Janeiro: Civilização Brasileira, 2003. 
CALDEIRA, Teresa. A presença do autor e a pós-modernidade em antropologia. Novos Estudos Cebrap, São Paulo, n. 21, jul. 1988, p. 133-157.

CARDOSO, Lívia; PARAÍSO, Marlucy. Tecnologia de gênero e a produção de sujeitos no currículo de aulas experimentais de ciências. Currículo sem Fronteiras, v. 15, n. 1, jan./abr. 2015, p. 155-177.

CARVALHAR, Danielle. Relações de gênero no currículo da educação infantil: a produção das identidades de princesas, heróis e sapos. 2009. Dissertação (Mestrado em Educação) - Universidade Federal de Minas Gerais, Belo Horizonte, 2009.

CARVALHO, Marília. 0 conceito de gênero no dia a dia da sala de aula. Revista de Educação Pública, Cuiabá, v. 21, n. 46, maio/ ago. 2012, p. 401-412.

CLIFFORD, James. A experiência etnográfica: antropologia e literatura no século XX. Rio de Janeiro: UFRJ, 2008.

CORAZZA, Sandra. Infância \& educação: era uma vez... quer que conte outra vez? 1. ed. Petrópolis: Vozes, 2002.

FINCO, Daniela. Encontro com as diferenças na educação infantil: meninos e meninas nas fronteiras de gênero. Leitura: Teoria \& Prática, Campinas, v. 31, n. 61, nov. 2013, p. 169-184.

FOUCAULT, Michel. Sobre a história da sexualidade. In: MACHADO, Roberto. Microfísica do poder. Rio de Janeiro: Graal, 2000. p. 243-276.

FOUCAULT, Michel. Verdade e subjetividade. Revista de Comunicação e Linguagem, Lisboa, n. 19, 1993, p. 202-223.

FRAGA, Alex. A boa forma de João e o estilo de vida de Fernanda. In: LOURO, Guacira; FELIPE, Jane; GOELLNER, Silvana. Corpo, gênero e sexualidade: um debate contemporâneo em educação. Petrópolis: Vozes, 2005. p. 135-150.

FREITAS, Daniela. 0 discurso da educação escolar nas histórias em quadrinhos do Chico Bento. Dissertação (Mestrado em Educação) - Universidade Federal de Minas Gerais, Belo Horizonte, 2008.

FURLANI, Jimena. Educação sexual: possibilidades didáticas. In: LOURO, Guacira; FELIPE, Jane; GOELLNER, Silvana. Corpo, gênero e sexualidade: um debate contemporâneo em educação. Petrópolis: Vozes, 2005. p. 66-81.

GEERTZ, Clifford. A interpretação das culturas. Rio de Janeiro: LTC,1989.

LARROSA, Jorge. Tecnologias do eu e educação. In: SILVA, Tomaz Tadeu (Org.). 0 sujeito da educação: estudos foucaultianos. Petrópolis: Vozes, 1994. p. 35-86.

LAURETIS, Teresa de. A tecnologia do gênero. In: HOLLANDA, Heloisa (Org.). Tendências e impasses: o feminismo como crítica da cultura. Rio de Janeiro: Rocco, 1994. p. 206-241.

LOURO, Guacira. Conhecer, pesquisar, escrever... Educação, Sociedade \& Culturas, Porto, n. 25, 2007, p. 235-245.

LOURO, Guacira. Gênero, sexualidade e educação. Petrópolis: Vozes, 1997 a.

LOURO, Guacira. Mulheres na sala de aula. In: DEL PRIORE, Mary (Org.). História das mulheres no Brasil. São Paulo: Contexto: 1997b. p. 443-481.

LUZ, Nanci. Violência contra a mulher: um desafio à concretização dos direitos humanos. In: LUZ, Nanci; Carvalho, Marília. CASAGRANDE, Lindamir. Construindo a igualdade na diversidade: gênero e sexualidade na escola. Curitiba: UTFPR, 2009. p. 193-208.

MEYER, Dagmar. Do poder ao gênero: uma articulação teórico-analítica. In: LOPES, Marta; MEYER, Dagmar; WALDOW, Vera (Org.). Gênero \& saúde. Porto Alegre: Artes Médicas, 1996. p. 41-51.

NICHOLSON, Linda. Interpretando o gênero. Estudos Feministas, Florianópolis, v. 8, n. 2, p. 9-41, 2000. 
PARAÍSO, Marlucy. Metodologias de pesquisas pós-críticas em educação e currículo: trajetórias, pressupostos, procedimentos e estratégias analíticas. In: MEYER, Dagmar; PARAíSO, Marlucy. Metodologias de pesquisas pós-críticas em educação. Belo Horizonte: Mazza, 2012. p. 23-46.

PRINS, Baukje; MEIJER, Irene Costera. Como os corpos se tornam matéria: entrevista com Judith Butler. Revista Estudos Feministas, Florianópolis, v. 10, n. 1, p. 155-167, 2002.

RABINOW, Paul. Antropologia da razão. Rio de Janeiro: Relume Dumará, 2002.

REIS, Cristina. Currículo escolar e gênero: a constituição generificada de corpos e posições de sujeito meninos-alunos. Dissertação (Mestrado em Educação) - Universidade Federal de Minas gerais, Belo Horizonte, 2011.

ROSE, Nikolas. Inventando nossos eus. In: SILVA, Tomaz Tadeu da. Nunca fomos humanos: nos rastros do sujeito. Belo Horizonte: Autêntica, 2001. p. 137-204.

SALES, Shirlei. Orkut.com.escol@: currículos e ciborguização juvenil. Tese (Doutorado em Educação) - Universidade Federal de Minas Gerais, Belo Horizonte, 2010.

SANTOS, Cláudia Amaral. A invenção da infância generificada: a pedagogia da mídia impressa constituindo as identidades de gênero. Dissertação (Mestrado em Educação) - Universidade Federal do Rio Grande do Sul, Porto Alegre, 2004.

SCOT, Joan. Gênero: uma categoria útil de análise histórica. Educação \& Realidade, Porto Alegre, v. 20, n. 2, p. 71-99, jul./dez. 1995.

SILVA, Tomaz Tadeu. A produção social da identidade e da diferença. In: SILVA, Tomaz Tadeu da. Identidade e diferença. Petrópolis: Vozes, 2000. p. 73-102.

SILVA, Tomaz Tadeu da. Documentos de identidade: uma introdução às teorias do currículo. Belo Horizonte: Autêntica, 2001.

WALKERDINE, Valerie. 0 raciocínio em tempos pós-modernos. Educação \& Realidade, Porto Alegre, v. 20, n. 2, p. 207-226, jul./ dez. 1995.

Recebido em: 20.07.2015

Aprovado em: 17.11.2015

Maria Carolina da Silva Caldeira é doutora em educação pela Faculdade de Educação da Universidade Federal de Minas Gerais (UFMG). É professora do Centro Pedagógico da Escola de Educação Básica e Profissional (CP/EBAP/UFMG).

Marlucy Alves Paraíso é professora associada do Departamento de Administração Escolar e do Programa de Pós-Graduação em Educação da Faculdade de Educação da Universidade Federal de Minas Gerais (UFMG). É fundadora e atual coordenadora do Grupo de Estudos e Pesquisas em Currículos e Culturas (GECC) da UFMG. 